\title{
Sex-linked inheritance of endosulphan resistance in Helicoverpa armigera
}

\author{
J OANNE C. DALY* \& J ENNIFER H. FISK \\ CSIRO Division of Entomology, GPO Box 1700, Canberra, ACT, 2601, Australia
}

\begin{abstract}
Endosulphan resistance is common in Australian populations of Helicoverpa armigera (Hübner), but resistance frequencies have not increased above $10-40 \%$ of the population, despite widespread use of this insecticide. We examined the inheritance of endosulphan resistance as part of a study of its evolution. Two field-resistant strains were selected in the laboratory. Results from a series of $\mathrm{F}_{1} \mathrm{~s}$ and backcrosses in both larvae and adults indicated that resistance was sex-linked, with almost complete dosage compensation in the hemizygous females. In males, resistance was partially dominant in fourth instar larvae but semi-recessive in adults. Estimates of resistance factors depended on the life stage and instar tested and on the bioassay method used. In larvae, resistance factors were highest in neonates (14-fold) and then declined to twofold in fifth instar larvae. Our results indicate that the genetic basis of resistance should enhance the rate of evolution in field populations compared with an autosomal locus.
\end{abstract}

Keyw ords: endosulphan resistance, Helicoverpa armigera, sex-linked resistance.

\section{Introduction}

Insecticide resistance provides a good model for the study of evolution in natural populations (McKenzie, 1996). This is because phenotypic differences are usually caused by major genes, and changes in allele frequencies are measurable over periods of 3-5 years. These changes arise from an interaction of the biological characteristics of the insect - those that determine effective population size and rates of gene flow - with characteristics of the resistance alleles, such as relative dominance, relative fitness or linkage relationships.

In insects, resistance alleles are rarely sex-linked (for examples, see Heather, 1986; McDonald \& Schmidt, 1987; Argentine et al., 1989; Brun et al., 1995), so the consequences of this mode of inheritance on the evolution of resistance have not been well documented. However, from theoretical studies, Avery (1984) showed that directional selection for a sex-linked trait could lead to more rapid increases in allele frequency than if the allele was autosomal. This hypothesis has recently been supported by Follet et al. (1995), who modelled rates of adaptation to permethrin in field populations of Colorado potato beetle Leptinotarsa decemlineata (Say) for a

\footnotetext{
*Correspondence. E-mail: joanned@ento.csiro.au
}

sex-linked trait. In contrast, McDonald \& Schmidt (1987, 1990) proposed that sex-linked resistance in the horn fly Haematobia irritans (L.) could retard the rate of evolution compared with autosomally inherited traits.

Daly (1992) provided preliminary evidence that resistance to the cyclodiene insecticide, endosulphan, in Helicoverpa armigera (Hübner) is sex-linked. Detailed studies in this species, on both its ecology (Fitt, 1989) and the evolution of pyrethroid resistance (Daly, 1993; Forrester et al., 1993), provide an opportunity to explore hypotheses about the importance of genetic factors on the evolution of endosulphan resistance in natural populations, because resistance to the two insecticides evolved concurrently during the 1980s in field populations of H. armigera in eastern Australia.

In response to the emergence of pyrethroid resistance throughout eastern Australia in 1983, the Australian Resistance Management Strategy for Helicoverpa control was introduced to delay the further development of resistance to both pyrethroids and endosulphan (Forrester et al., 1993). The impact of the strategy on the subsequent evolution of pyrethroid resistance has been well described (Daly, 1993; Forrester et al., 1993) but, to date, there is limited evidence of its impact on endosulphan resistance. 
Resistance to cyclodiene insecticides (endrin, endosulphan and toxaphene) in $H$. armigera was common and widespread in the early 1970s (Goodyer et al., 1975). Resistance frequencies declined to almost undetectable levels in field populations during 1979-83 when endosulphan was replaced by pyrethroids, and other cyclodienes were deregistered (Forrester et al., 1993; Gunning \& Easton, 1994). Endosulphan use increased after 1984 in response to widespread pyrethroid resistance.

Despite the general association between the use of cyclodienes and the presence of resistance, the frequency of endosulphan resistance has not increased to high levels, in contrast to pyrethroid resistance (Daly, 1993; Forrester et al., 1993). Until 1991, the frequency of resistant individuals fluctuated from $10 \%$ to $30 \%$ in populations sampled in the Namoi/Gwydir area of New South Wales, even though over $50 \%$ of pesticide applications for Helicoverpa control in cotton crops were with endosulphan. Frequencies have increased more recently, so that, by 1995 , they reached $40 \%$ by late summer (Forrester \& Bird, 1996). In contrast, pyrethroid resistance rose from maximum frequencies of around $15 \%$ in 1983 to $80-90 \%$ by 1995 , even though pyrethroid applications account for less than $20 \%$ of insecticide applications in cotton crops (Forrester et al., 1993; Gunning \& Easton, 1994).

In addition to this year-to-year variation, frequencies of both endosulphan and pyrethroid resistance increase from spring to autumn, in association with the use of insecticides (Forrester \& Bird, 1996), but they usually decline in the first spring generation after winter diapause, probably because of dilution from an influx of susceptible individuals into the cropping regions (Daly, 1993; Forrester et al., 1993).

Forrester et al. (1993) proposed a number of hypotheses to account for the difference in evolutionary response between pyrethroid and endosulphan resistance. First, selection pressure could be lower for endosulphan resistance, because it is used predominantly in springtime when a sibling species, $H$. punctigera (Wallengren), is the dominant pest species, compared with the pyrethroids, which are used in mid-summer when $H$. armigera becomes more common. Secondly, endosulphan resistance may have reduced fitness in the absence of insecticide. Thirdly, the mode of inheritance and relative dominance of resistance alleles could differ between endosulphan and pyrethroid resistance. Another hypothesis could be that the discrimination in the field between genotypes may be less with endosulphan resistance than it is with pyrethroid resistance.
In this paper, we examine the third of these hypotheses - that the slower loss of susceptibility to endosulphan is a result of the mode of inheritance and expression of resistance. Daly (1992) reported preliminary evidence for the fourth hypothesis that discrimination between genotypes under field selection is poor in larvae.

\section{Materials and methods}

\section{Strains}

Rearing techniques for $H$. armigera strains in the laboratory are given in Daly \& Fisk (1992). Two endosulphan-resistant strains were derived from individuals collected by N. W. Forrester (New South Wales Department of Agriculture, Narrabri) as part of his resistance monitoring programme (Forrester et al., 1993). Resist-1 was collected in midsummer and resist-2 was collected in the spring of the 1989/90 cotton season. The level of resistance in these strains was increased after a series of selections at 2, 20 and $40 \mu \mathrm{g}$ per larva of endosulphan. The endosulphan-susceptible strain, suscept-1, was also susceptible to pyrethroids, whereas a second strain, suscept-2, was homozygous for metabolic resistance to pyrethroids (called susceptible and field, respectively, in Daly \& Fisk, 1992).

$\mathrm{F}_{1} \mathrm{~S}$ and backcrosses were carried out in larvae using resist-1 and suscept-1 strains. All other experiments, including bioassays in adults and the Potter tower experiments, used the resist-2 and suscept- 2 strains, because they were healthier.

The parent resist-2 line was selected for five generations at the $\mathrm{LD}_{75}, 80 \mu \mathrm{g}$ per larva of endosulphan, using topical application on fourth instars. Survivors of the selecting dose were reared and mass-mated. An unselected line was kept as a control. Larvae from the selected strain were bioassayed each generation. Adults were bioassayed in the first and fifth generations.

\section{Bioassays}

We used three techniques to assay resistance in $H$. armigera.

1 Fourth instar larvae $28-40 \mathrm{mg}$ in body mass were tested using a topical application of $1 \mu \mathrm{L}$ of a solution of endosulphan (technical grade; Hoechst Australia Ltd, Sydney, Australia) dissolved in acetone (Daly \& Fisk, 1992). Survivors were classified as resistant.

2 Larvae from hatchlings to 10-day-olds were exposed to cotton leaves, Gossypium hirsutum, culti- 
var Deltapine 90, treated with a $0.5 \mathrm{~mL}$ solution of endosulphan applied using a Potter tower (Burkard Manufacturing, UK). All dilutions were a mixture of acetone, ethanol, white oil, $0.05 \%$ Triton $\mathrm{X}$ in water, in the ratio 1:1:2:6. The white oil and Triton $X$ were needed to increase the solubility of endosulphan at high concentrations. Cotton leaves were sampled from the third to the fifth nodes. Treated leaf discs were allowed to dry, between one and five larvae were put onto the treated surface, and then the disc was placed over the top of a $30 \mathrm{~mL}$ plastic container, treated surface facing inwards, and the container was sealed with a snap lid. Mortality was recorded after $48 \mathrm{~h}$ and moribund larvae were counted as dead.

3 Adults were tested using the adult vial test, described in detail in Daly \& Fisk (1993). A $0.5 \mathrm{~mL}$ solution of acetone with dissolved endosulphan was added to each vial. The concentration of endosulphan per vial was between 0.3 and $100 \mu \mathrm{g}$. Prepared vials were stored at $4^{\circ} \mathrm{C}$ for up to 14 days until required. Adults were scored after 2 days; individuals that were dead, moribund or showed uncoordinated movements were all counted as dead.

\section{Analysis}

All statistical analyses were performed using the statistical program GLIM 3.77 (Payne, 1985). A logit transformation was used for the analysis of all doseresponse bioassay data.

\section{Sex-linked resistance in $\mathrm{H}$. armigera}

In $H$. armigera, females are $\mathrm{XY}$ and males $\mathrm{XX}$, as is the case in most Lepidoptera (White, 1973; Fisk, 1992). If a resistance locus is on the $X$ chromosome, the dose-response of the $F_{1}$ generation will differ between the reciprocal crosses, and male and female progeny will have different genotypes and phenotypes, as given in Table 1 . In both crosses, sons would be heterozygous $\left(\mathrm{X}^{R} \mathrm{X}^{r}\right)$, but daughters will be hemizygous resistant $\left(\mathrm{X}^{R} \mathrm{Y}\right)$ or susceptible $\left(\mathrm{X}^{r} \mathrm{Y}\right)$, depending on the father's genotype. However, as larvae are difficult to sex, it is not possible to determine directly the phenotype of heterozygous males in this life stage.

Backcrosses also yield different results depending on the direction of cross. The types of backcrosses that were informative and their predicted outcomes are given in Table 1. Data were not available for backcross $\mathrm{D}$ in the larval stage. Backcross lines were compared with the appropriate susceptible or $F_{1}$ line using GLIM log-linear regression.

\section{Results}

\section{Fourth instar larvae with topical dose test}

Bioassay results for fourth instar larvae are given in Table 2. Overall, resistance factors in the topical dose test in fourth instar larvae were calculated to be 42-fold and 62-fold in the two lines. There was no significant difference between the two susceptible lines $\left(F_{1,33}=0.2, P>0.05\right)$, but significant differences were observed between the two resistant strains $\left(F_{1,26}=6.3, P<0.05\right)$. The resist-2 strain, which had been subject to stronger selection in the laboratory, had a higher $\mathrm{LD}_{50}$ and a steeper slope. However, there was no change in dose-response after five generations of selection: generation $1\left(\mathrm{LD}_{50}=45 \mu \mathrm{g}\right.$ per larva, slope 2.2) compared with generation 5 $\left(\mathrm{LD}_{50}=45 \mu \mathrm{g}\right.$ per larva, slope $\left.2.0 ; \chi_{1}^{2}=0.0, P>0.05\right)$.

The two reciprocal $F_{1}$ crosses were significantly different from each other $\left(F_{1,27}=118, P<0.001\right)$.

Table 1 Predicted progeny in $\mathrm{F}_{1}$ crosses and backcrosses for sex-linked endosulphan resistance in Helicoverpa armigera [females are the heterogametic sex (XY) and males are homogametic (XX)]

Predicted phenotype

\begin{tabular}{|c|c|c|c|}
\hline \multirow[b]{2}{*}{ Cross } & \multirow[b]{2}{*}{ Genotype of progeny } & \\
\hline & & Larvae & Adults \\
\hline \multicolumn{4}{|l|}{$\mathrm{F}_{1}$} \\
\hline A. $\left(\mathrm{X}^{r} \mathrm{X}^{r} \times \mathrm{X}^{R} \mathrm{Y}\right)$ & $\mathrm{X}^{R} \mathrm{X}^{r}, \mathrm{X}^{\prime} \mathrm{Y}$ & Low $\mathrm{F}_{1}$ line & Heterozygous $\hat{\rho}$, susceptible 9 \\
\hline B. $\left(\mathrm{X}^{R} \mathrm{X}^{R} \times \mathrm{X}^{\prime} \mathrm{Y}\right)$ & $\mathrm{X}^{R} \mathrm{X}^{r}, \mathrm{X}^{R} \mathrm{Y}$ & High $F_{1}$ line & Heterozygous $\hat{\alpha}$, resistant $q$ \\
\hline \multicolumn{4}{|l|}{ Backcrosses } \\
\hline A. $\mathrm{X}^{r} \mathrm{X}^{r} \times\left(\mathrm{X}^{r} \mathrm{X}^{r} \times \mathrm{X}^{R} \mathrm{Y}\right)$ & $\mathrm{X}^{r} \mathrm{X}^{r}, \mathrm{X}^{r} \mathrm{Y}$ & All susceptible & All susceptible \\
\hline B. $\mathrm{X}^{r} \mathrm{X}^{r} \times\left(\mathrm{X}^{R} \mathrm{X}^{R} \times \mathrm{X}^{r} \mathrm{Y}\right)$ & $\mathrm{X}^{R} \mathrm{X}^{r}, \mathrm{X}^{r} \mathrm{Y}$ & Low $\mathrm{F}_{1}$ line & Heterozygous $\hat{\alpha}$, susceptible $q$ \\
\hline C. $\mathrm{X}^{R} \mathrm{X}^{R} \times\left(\mathrm{X}^{r} \mathrm{X}^{r} \times \mathrm{X}^{R} \mathrm{Y}\right)$ & $\mathrm{X}^{R} \mathrm{X}^{r}, \mathrm{X}^{R} \mathrm{Y}$ & High $\mathrm{F}_{1}$ line & Heterozygous $\hat{\alpha}$, resistant $\phi$ \\
\hline D. $\mathrm{X}^{R} \mathrm{X}^{R} \times\left(\mathrm{X}^{R} \mathrm{X}^{R} \times \mathrm{X}^{\prime} \mathrm{Y}\right)$ & $\mathrm{X}^{R} \mathrm{X}^{R}, \mathrm{X}^{R} \mathrm{Y}$ & All resistant & All resistant \\
\hline
\end{tabular}


Table 2 Dose-response of fourth instar larvae of Helicoverpa armigera to topical application of endosulphan (crosses are given in Table 1)

\begin{tabular}{lcccc}
\hline Strain & $\begin{array}{c}\mathrm{LD}_{50} \\
(\mu \text { g per larva })\end{array}$ & $95 \% \mathrm{CI}$ & Slope & $\mathrm{RF}$ \\
\hline Suscept-1 & 1.0 & $0.9,1.1$ & 2.3 & \\
Suscept-2 & 0.9 & $0.8,1.0$ & 2.8 & \\
Backcross A susceptibles & 0.9 & $0.8,1.0$ & 2.5 & \\
Resist-1 & 42 & 36,48 & 1.5 & $\times 42$ \\
Resist-2 & 54 & 49,60 & 2.5 & $\times 62$ \\
$\mathrm{~F}_{1} \mathrm{~A}-$ low $\mathrm{F}_{1}$ & 3.9 & $3.1,4.9$ & 1.0 & \\
Backcross B - low $\mathrm{F}_{1}$ & 1.8 & $1.5,2.2$ & 1.0 & \\
$\mathrm{~F}_{1} \mathrm{~B}-$ high $\mathrm{F}_{1}$ & 37 & 30,46 & 1.0 & \\
Backcross C - high $\mathrm{F}_{1}$ & 46 & 34,62 & 1.3 & \\
\hline
\end{tabular}

The low slope and the difference in $\mathrm{LD}_{50}$ of the two crosses, 10-fold in this case, is consistent with sex-linked inheritance of resistance. The $\mathrm{LD}_{50}$ from the $\mathrm{F}_{1} \mathrm{~B}$ cross, $37 \mu \mathrm{g}$ per larvae, is similar to that in the parental resistance lines, $42-54 \mu \mathrm{g}$ per larvae, which is consistent with partial dominance of a sex-linked trait.

The backcross data also support the sex-linked inheritance of resistance in larvae (Table 2). Backcrosses $\mathrm{A}$ and $\mathrm{C}$ produced progeny with the predicted dose-response curve for sex-linked inheritance (Table 2) $\left(F_{1,29}=0.5, \quad P>0.05\right.$, susceptible parents cf. backcross $\mathrm{A} ; F_{1,17}=2.4, P>0.05$, high $\mathrm{F}_{1}$ cf. backcross $\mathrm{C}$ ). There were significant differences between the 'low $\mathrm{F}_{1}$ ' produced by the backcross $\mathrm{B}$ and the original low $\mathrm{F}_{1}$ line $\left(F_{1,36}=18, P<0.01\right)$, but the differences in $\mathrm{LD}_{50}$ were small.

\section{Dose-response in adults}

Bioassay data for adults are given in Table 3. These data provide further evidence that the resistance is sex-linked. However, there appears to be extra variation from the susceptible strains that contributes to the expression of resistance in hybrid crosses.

Resistance factors in fully resistant adults were 22 -fold in females and 30-fold in males. The differences between males and females were small and,

Table 3 Dose-response of adult Helicoverpa armigera (the crosses are as given in Table 1)

\begin{tabular}{llcccc}
\hline Strain & Sex & $\begin{array}{c}\text { LD }_{50} \\
\text { (p.p.m.) }\end{array}$ & 95\% CI & Slope & RF \\
\hline Susceptible & Male & 8.8 & $8.1,9.6$ & 3.7 & \\
& Female & 9.2 & $8.5,9.9$ & 3.7 & \\
& Combined & 8.9 & $8.5,9.5$ & 3.7 & \\
Resistant & Male & 266 & 244,289 & 1.8 & 30 \\
& Female & 205 & 186,224 & 1.8 & 22 \\
& Combined & 250 & 226,276 & 2.0 & 28 \\
F $_{1}$ & & & & & \\
A & Susceptible daughters & 13.8 & $13.1,14.4$ & 3.9 & \\
& Heterozygous sons & 66 & 61,71 & 2.3 & 7.5 \\
B & Resistant daughters & 310 & 270,357 & 2.6 & 23 \\
& Heterozygous sons & 62 & 58,68 & 2.3 & 7.0 \\
Backcrosses & & & & & \\
A and B & Susceptible offspring & 12.4 & $11.8,13.0$ & 4.1 & \\
B and C & Heterozgygous males & 51 & 47,55 & 4.6 & \\
C and D & Resistant daughters & 370 & 330,415 & 3.5 & \\
D & Resistant sons & 497 & 410,602 & 2.8 & \\
\hline
\end{tabular}

(c) Commonwealth Scientific Industrial Research Organisation, Heredity, 81, 55-62. 
although these differences were not statistically significant in either the susceptible $\left(F_{1,30}=0.2\right.$, $P>0.05)$ or the resistant strains $\left(F_{1,106}=2.4\right.$, $P>0.05)$ analysed, resistant males were consistently more tolerant of endosulphan than were females (see Table 3).

Data from single-pair crosses provide evidence for extra genetic variation that contributes to the resistant phenotype. Five single-pair crosses of type $\left(\mathrm{X}^{R} \mathrm{X}^{R} \times \mathrm{X}^{R} \mathrm{Y}\right)$ yielded estimates of $\mathrm{LD}_{50}$ from 119 to 267 p.p.m. in females and from 185 to 444 p.p.m. in males. Three of these crosses were reared as isofemale lines over three generations. They maintained their relative differences during subsequent generations $\left(F_{5,34}=3.6, \quad P<0.05\right.$; for differences between lines over generations). For example, the $\mathrm{LD}_{50} \mathrm{~s}$ for isofemale line 1 were 156, 139 and 91 p.p.m. compared with 331, 406 and 425 p.p.m. for isofemale line 2. Nevertheless, after five generations of selection in the parental resist- 2 strain, there was no increase in resistance levels. Indeed, there was a small but significant drop $\left(F_{1,15}=17, P<0.01\right)$ in $\mathrm{LD}_{50}$ between generation 1 (399 p.p.m.) and generation 5 (280 p.p.m.). The unselected control strain had an $\mathrm{LD}_{50}$ after five generations of 183 p.p.m.

Results in the $F_{1}$ crosses indicate the importance of genetic background on phenotype. $F_{1}$ crosses yielded heterozygous sons (sevenfold) and either resistant (23-fold) or susceptible daughters. Although there was no significant difference in the $\mathrm{LD}_{50}$ between $\mathrm{F}_{1}$ males from either direction of cross
(Table 3; $F_{1,50}=0.1, P>0.05$ ), the $\mathrm{LD}_{50} \mathrm{~s}$ of the susceptible and resistant $F_{1}$ females were about 1.5 -fold greater than those observed in the parental strains for both susceptible $\left(F_{1,27}=11, P<0.01\right.$, for differences in $\left.\mathrm{LD}_{50}\right)$ and resistant strains $\left(F_{1,35}=2.5\right.$, $P>0.05)$. Thus, hybrid females were more tolerant of endosulphan compared with females in the original parent strains, although the difference was only significant for susceptible genotypes (see above). These differences were evident in the four estimates of $\mathrm{LD}_{50} \mathrm{~s}$ for single-pair crosses of $\mathrm{F}_{1}$ resistant daughters $\left(\mathrm{X}^{R} \mathrm{X}^{R} \times \mathrm{X}^{r} \mathrm{Y}\right)$ - they ranged from 512 to 817 p.p.m., all of which were greater than those obtained in mass matings above.

In the backcross generation, the progeny of each cross exhibited the predicted phenotype for sex-linked inheritance, given in Table 2, except that again the $\mathrm{LD}_{50}$ values of the backcross homozygous males and hemizygous females were 1.5- to twofold higher relative to the original parental values (Table 3).

\section{Dose-response of first to fourth instars using Potter tower}

The dose-responses of larvae exposed to treated leaves are given in Table 4. An age range of 0 to 10 days old corresponds to first to early fifth instar; and 7-day-old larvae are fourth instar, the same age as larvae treated with the topical dose test. The $\mathrm{LC}_{50} \mathrm{~S}$ increased within each strain as larvae

Table 4 Comparison of dose-response of susceptible and resistant Helicoverpa armigera larvae exposed to cotton leaves treated with endosulphan

\begin{tabular}{llrccc}
\hline $\begin{array}{l}\text { Age of larvae } \\
(\text { days)* }\end{array}$ & Strain & $\begin{array}{c}\text { LC }_{50} \\
\text { (p.p.m.) }\end{array}$ & $95 \%$ CI & Slope & RF \\
\hline 0 & Susceptible & 39 & 32,47 & 1.9 & \\
& Resistant & 547 & 451,664 & 1.9 & 14 \\
2 & Susceptible & 249 & 195,1280 & 1.6 & \\
& Resistant & 1620 & 1280,2050 & 1.6 & 6.5 \\
3 & Susceptible & 499 & 425,587 & 2.8 & \\
& Resistant & 3220 & 2780,3730 & 2.8 & 6.5 \\
5 & Susceptible & 941 & 771,1150 & 2.3 & \\
& Resistant & 4870 & 4020,5900 & 2.3 & 5.2 \\
7 & Susceptible & 2340 & 2040,2681 & 4.9 & \\
& Resistant & 10310 & 8990,11825 & 4.9 & 4.4 \\
10 & Susceptible & 5656 & 4663,6862 & 2.9 & \\
& Resistant & 11871 & 10013,14074 & 2.9 & 2.1 \\
\hline
\end{tabular}

*Ages $0,2,3,5,7$ and 10 days old correspond to first, early second, late second, third, fourth and fifth instars, respectively. 
increased age: 146-fold within the susceptible strain, but only 22 -fold within the resistant strain. Thus, the differences between resistant and susceptible insects at a given age were greatest in neonates (14-fold) and decreased to 2.1-fold by early fifth instar, 10-day-old larvae. Overall, resistance factors were lower than those observed with the topical dose test for fourth instar larvae (62-fold) compared with those observed with larvae on treated leaves (4.4-fold).

Neonate larvae died when exposed to endosulphan with only minimal or no signs of feeding. However, in larger larvae, particularly at 10 days old, significant amounts of feeding were observed even at concentrations of endosulphan that led to $95 \%$ mortality.

\section{Sex-linkage and frequency of resistance}

The frequencies of genotypes were calculated for a hypothetical resistance gene $R$ : for either a sex-linked or an autosomal locus. It was assumed that (i) all genotypes were in Hardy-Weinberg equilibrium; (ii) the heterozygotes had intermediate expression; and (iii) full dosage compensation occurred at the sex-linked locus. The relative abundance of fully resistant individuals given the sex-linked locus $\left(\mathrm{X}^{R} \mathrm{Y}\right.$ plus $\mathrm{X}^{R} \mathrm{X}^{R}$ individuals) was compared with the autosomal locus ( $R R$ individuals) at a range of allele frequencies from $10^{-5}$ to $10^{2}$. At $10^{-5}$, there were 10000 times more fully resistant individuals in the population if the allele was sex-linked rather than autosomal. The difference between sex-linked and autosomal loci disappeared rapidly as the allele became common. Note, however, that if all resistant genotypes $\left(\mathrm{X}^{R} \mathrm{X}^{R}, \mathrm{X}^{R} \mathrm{Y}\right.$ and $\left.\mathrm{X}^{R} \mathrm{X}^{r}\right)$ are taken into account, then the relative abundance of resistant individuals is similar for both sex-linked and autosomal loci.

\section{Discussion}

Our results confirm that the major genetic factor for endosulphan resistance is sex-linked. The simplest hypothesis is that resistance is conferred by a single, major gene. At this stage, however, it is not possible to exclude a more complex mode of inheritance, namely that resistance is determined by a group of closely linked genes on the $\mathrm{X}$ chromosome. Furthermore, in the $\mathrm{F}_{1} \mathrm{~s}$ and backcrosses, evidence of further genetic variation that contributes to the resistance phenotype was found. The nature of this variation is not defined, nor subject to further study at this time. Chromosomal mapping (see below) may help to resolve the relative contribution of other genes to the expression of resistance.

Estimates of resistance factors conferred by the major gene varied depending on the life stage tested and on the technique used. Differences between susceptible and resistant insects were smaller when larvae were exposed to treated leaves compared with the topical dose test. The former bioassay technique resembles more closely exposure of insects under field conditions in which larvae move across and eat treated plants. Thus, our results in the laboratory indicate that discrimination between resistant and susceptible larvae under field conditions may be poor, except in neonate larvae.

Forrester et al. (1993) summarized earlier reports on endosulphan resistance in $H$. armigera. Resistance factors for the period 1971-81 varied from twofold to 62-fold. These estimates were obtained from topical bioassays using fourth instar larvae collected from the field as part of resistance monitoring programmes, so a major source of variation in their estimates would be the genetic heterogeneity within each sample. These earlier studies did not identify the genetic basis of resistance, so it is not clear if the same loci have been involved in endosulphan resistance since the early 1970s. However, the magnitude of resistance factors in earlier studies is similar to that reported here.

The mechanism of endosulphan resistance in $H$. armigera is unknown, but Forrester et al. (1993) observed high levels of cross-resistance to other cyclodienes, dieldrin and endrin. ffrench-Constant et al. (1993) reported that cyclodiene resistance in a variety of Drosophila species and in other insects (Thompson et al., 1993) is associated with the $R d l$ gene that codes for the $\mathrm{GABA}_{\mathrm{A}}$ receptor. They observed that resistant and susceptible individuals in these species all appeared to differ by only a single basepair at this locus.

In contrast, Trowell et al. (1994) and Daly \& Trowell (1996) could find no difference in the $R d l$ gene in either susceptible or resistant $H$. armigera in the region described by ffrench-Constant et al. (1993). Furthermore, D. G. Heckel and L. J. Gahan (pers. comm.) have constructed linkage maps for two closely related heliothine species, $H$. zea and Heliothis virescens, and the $R d l$ gene is not sex-linked in these two species. This evidence taken together would suggest that the $R d l$ locus is not involved in sex-linked cyclodiene resistance in $H$. armigera.

Forrester et al. (1993) hypothesized that the mode of expression of endosulphan resistance might be one possible explanation for the gradual loss of susceptibility, compared with the situation with 
pyrethroid resistance. This hypothesis has been proposed for the evolution of sex-linked permethrin resistance in the horn fly Haematobia irritans (L.). McDonald \& Schmidt (1987, 1990) suggested that a combination of an almost completely recessive resistance locus linked to a sex-determining locus would delay the establishment of resistance in the horn fly because, initially, males could not be homozygous for resistance, and females would all be susceptible. Their conclusions, however, are dependent on the sex-determining system of some muscoid flies, such as the horn fly, in which sex is determined by a single locus rather than by the $\mathrm{XX} / \mathrm{XY}$ or $\mathrm{XX} / \mathrm{XO}$ chromosome complement that is more typical of insects.

Our results suggest that, in $H$. armigera, the sex-linked mode of endosulphan resistance should enhance, rather than retard, the rate of evolution for two reasons, as was proposed by Avery (1984). First, dosage compensation occurs in females, so that even at low frequencies of the $\mathrm{X}^{R}$ allele, fully resistant females $\left(\mathrm{X}^{R} \mathrm{Y}\right)$ would be present, a situation not normally found with an autosomal locus until resistance reaches appreciable frequencies. Secondly, resistance is partially dominant in larvae, so that $\mathrm{X}^{R} \mathrm{X}^{r}$ males have a resistant phenotype.

Yet the field data indicate that the average frequency of resistance year by year has been slow to increase (Forrester \& Bird, 1996), although there is some indirect evidence that selection is operating in field populations. Phenotype frequencies do change within a season in association with the use of endosulphan in spring and summer (Forrester \& Bird, 1996). So, why has intraseasonal variation in endosulphan not led to a more rapid increase in resistance frequencies, as has been observed with pyrethroid resistance?

We hypothesize that other factors are also important. Daly (1992) reported that, in the field, poor discrimination between phenotypes occurred in larvae. Mortality of all phenotypes was high when very young larvae were exposed to cotton plants freshly exposed to commercial applications of endosulphan. Two days later, however, all phenotypes had high survival when exposed to the same plants. Thus, the window for selection appears to be small in field populations, smaller than that observed for pyrethroid resistance (Daly, 1993).

Monitoring data for resistance may also be giving a biased view of intraseasonal changes. Sampling is generally restricted to populations found in cotton fields where endosulphan is used (Forrester et al., 1993). But $H$. armigera is polyphagous, and many alternative hosts, which are not sprayed with insecti- cide, exist in spring and early summer (Fitt, 1989) when endosulphan usage is high. In midsummer, few alternative hosts exist, yet this coincides with the period of maximum pyrethroid usage. Thus, in these terms, although endosulphan resistance frequencies increase in response to selection in cotton fields, less of the total population in a region would be under selection compared with the situation with pyrethroid resistance. Thus, the observed increases in endosulphan resistance within a season may be overestimated relative to those observed for pyrethroid resistance.

In conclusion, although the genetic basis of resistance can influence the rate of evolution, the actual consequences of sex-linkage will depend on how sex is determined and on the relative dominance of the heterozygous and hemizygous individuals. Dominance relationships are not necessarily predictive of fitnesses of genotypes under selection in field populations (Daly, 1993; McKenzie, 1996).

\section{Acknow ledgements}

We thank Neil Forrester for his generosity in providing the original insect strains that we used for selections. Anna Grabowski assisted with the insect rearing, Chris Hunt with the illustrations and Michael Adena with the statistical analysis. Neil Forrester and Geoff Clarke provided valuable comments on an earlier draft of the manuscript. This work was supported, in part, by funds from the Australian Cotton Research and Development Corporation. We are grateful for their continuing support of research into insecticide resistance in $H$. armigera.

\section{References}

ARgentine, J. A., ClARK, J. M. AND FERro, D. N. 1989. Genetics and synergism of resistance to azinphosmethyl and permethrin in the Colorado potato beetle (Coleoptera: Chrysomelidae). J. Econ. Entomol., 82, 698-705. AVERY, P. J. 1984. The population genetics of haplodiploids and X-linked genes. Genet. Res., 44, 321-341.

BRUN, L. O., SUCKLING, D. M., ROUSH, R. T, GAUDICHON, v, PREISLER, H. AND ROBERTSON, J. 1995. Genetics of endosulfan resistance in Hypothenemus hamperi (Coleoptera: Scolytidae): implications for mode of sex determination. J. Econ. Entomol., 88, 470-474.

DALY, J. C. 1992. Endosulfan resistance in Helicoverpa armigera. In: Proceedings of 6th Australian Cotton Growers Research Association Cotton Conference, Broadbeach, Queensland, Australia, August 1994, pp. 353-358.

DALY, J. C. 1993. Ecology and genetics of insecticide resistance in Helicoverpa armigera: interactions between selection and gene flow. Genetica, 90, 217-226. 
DALY, J. C. AND FISK, J. H. 1992. Inheritance of metabolic resistance to the synthetic pyrethroids in Australian Helicoverpa armigera (Hübner) (Lepidoptera: Noctuidae). Bull. Ent. Res., 82, 5-12.

DALY, J. C. AND FISK, J. H. 1993. Expression of pyrethroid resistance in adult Helicoverpa armigera (Lepidoptera: Noctuidae) and selective mortality in field populations. Bull. Ent. Res., 83, 23-28.

DALY, J. C. AND TROWELL, s. 1996. Biochemical approaches to the study of ecological genetics: the role of selection and gene flow in the evolution of insecticide resistance. In: Symondson, W. O. C. and Liddell, J. E. (eds) The Ecology of Agricultural Pests: Biochemical Approaches, pp. 73-92. Chapman \& Hall, London.

FISK, J. H. 1992. Karyotype and achiasmate female meiosis in Helicoverpa armigera (Hübner) and $H$. punctigera (Wallengren) (Lepidoptera: Noctuidae). Genome, 32, 967-971.

FITT, G. P. 1989. The ecology of Heliothis species in relation to agro-ecosystems. Ann. Rev. Ent., 83, 1827-1836.

FOllet, P. A., GOULD, F. AND KENNEDY, G. C. 1995. Highrealism model of Colorado potato beetle (Coleoptera: Chrysomelidae) adaptation to permethrin. Environ. Entomol., 24, 167-178.

FFRENCH-CONSTANT, R. H., STEICHEN, J. C., ROCHELEAU, T. A., ARONSTEIN, K. AND ROUSH, R. T. 1993. A singleamino acid substitution in a $\gamma$-aminobutyric acid subtype A receptor locus is associated with cyclodiene insecticide resistance in Drosophila populations. Proc. Natl. Acad. Sci. U.S.A., 90, 1957-1961.

FORRESTER, N. W. AND BIRD, L. J. 1996. Conventional insecticide and $\mathrm{Bt}$ transgenic resistance management in Australian cotton. In: Proceedings of 8th Australian Cotton Growers Research Association Cotton Conference, Broadbeach, Queensland, Australia, August 1996, pp. 159-172.

FORRESTER, N. W., CAHILL, M., BIRD, L. J. AND LAYLAND, J. K. 1993. Management of pyrethroid and endosulfan resistance in Helicoverpa armigera (Lepidoptera:
Noctuidae) in Australia. Bull. Ent. Res., Suppl. 1, $1-132$.

GOODYER, G. J., WILSON, A. G. L., ATTIA, F. I. AND CLIFT, A. D. 1975. Insecticide resistance in Heliothis armigera (Hübner) (Lepidoptera: Noctuidae) in the Namoi Valley of New South Wales, Australia. J. Aust. Entomol. Soc., 14, 171-173.

GUNNING, R. V. AND EASTON, C. S. 1994. Endosulfan resistance in Helicoverpa armigera (Hübner) (Lepidoptera: Noctuidae) in Australia. J. Aust. Entomol. Soc., 33, 9-12.

HEATHER, N. w. 1986. Sex-linked resistance to pyrethroids in Sitophilus oryzae (L.) (Coleoptera: Curculionidae). $J$. Stored Prod. Res., 22, 15-20.

McDONALD, P. T. AND SCHMIDT, C. D. 1987. Genetics of permethrin resistance in the horn fly (Diptera: Muscidae). J. Econ. Entomol., 80, 433-437.

McDONALD, P. T. AND SCHMIDT, C. D. 1990. Linkage, expression and distribution of the pyrethroid resistance gene in the horn fly (Diptera: Muscidae). J. Econ. Entomol., 83, 1718-1722.

McKenZIE, J. A. 1996. Ecological and Evolutionary Aspects of Insecticide Resistance. R.G. Landes Company and Academic Press, Inc., Austin, TX.

PAYNE, C. D. 1985. The GLIM System release 3.77 Manual. Numerical Algorithms Group, Oxford.

THOMPSON, M., STEICHEN, J. C. AND FFRENCH-CONSTANT, R. H. 1993. Conservation of cyclodiene insecticide resistance associated with mutations in insects. Insect Mol. Biol., 2, 149-154.

TROWELL, S., ZINKOVSKY, E., DALY, J., RUSSELL, R. AND FFRENCH-CONSTANT, R. 1994. DNA probes for key insecticide resistance genes. 1. Endosulfan resistance in Australian H. armigera. In: Proceedings of 6th Australian Cotton Growers Research Association Cotton Conference, Broadbeach, Queensland, Australia, August 1994, pp. 21-26.

white, M. J. D. 1973. Animal Cytology and Evolution, 3rd edn. Cambridge University Press, Cambridge. 